\title{
The Social Conditions in the Genesis of Preeclampsia
}

\author{
Jaime Salvador-Moysén', Yolanda Martínez-López¹, José M. Ramírez-Aranda², \\ Marisela Aguilar-Durán1, Miguel A. Reyes-Romero ${ }^{3}$ \\ ${ }^{1}$ Scientific Research Institute, Universidad Juárez del Estado de Durango, Durango, México \\ ${ }^{2}$ Department of Family Medicine, University Hospital Dr. José Eleuterio González, Universidad Autónoma de \\ Nuevo León, Monterrey, México \\ ${ }^{3}$ Faculty of Medicine and Nutrition, Universidad Juárezdel Estado de Durango, Durango, México \\ Email: jsmoysen@gmail.com, ymtzlopez@gmail.com, ramirez0r0nd0@yahoo.com.mx, \\ aguilarduran marisela@hotmail.com, miguelrys@gmail.com
}

Received 21 May 2014; revised 22 June 2014; accepted 22 July 2014

Copyright (C 2014 by authors and Scientific Research Publishing Inc.

This work is licensed under the Creative Commons Attribution International License (CC BY). http://creativecommons.org/licenses/by/4.0/

c) (i) Open Access

\section{Abstract}

This article highlights the importance of preeclampsia as a global public health problem and the lack of a satisfactory model to explain its genesis. Scientific advances relevant to the placental pathophysiology, which have resulted in a deeper understanding of the immunological mechanisms associated to preeclampsia and have been translated into better treatment options, are also highlighted, although to date these approaches cannot explain the origin of the disease. From a theoretical approach underpinned by the concepts related to the social determinants of the health, and specifically from current psychosocial epidemiology, an alternative approach that gives account for the genesis of preeclampsia is proposed. The proposal is based in the scientific literature as well as in the work of the authors; it takes as references unfavorable socioeconomic and psychosocial conditions in pregnant women, linking these conditions to a series of failed adaptive biological processes closely related to an ineffective allostatic response by the body, which ultimately determines the occurrence of the disease.

\section{Keywords}

Preeclampsia, Psychosocial Epidemiology, Social Inequality, Allostasis, Neighborhood

\section{Introduction}

Preeclampsia is a serious public health problem that affects the group of pregnant women; the disease has severe obstetric and perinatal implications_-for decades has been located at the international level as one of the three 
major causes of maternal death—and shows prevalences varying between $2 \%$ and $8 \%$, variations that have a clear association with the grade of socioeconomic development of the different geographical locations where inhabit women in reproductive age [1] [2].

Although studies have been conducted almost all over the world in the last decades to determine the genesis of preeclampsia [3]-[7], there is still no satisfactory explanatory model that defines and links the biological, clinical, epidemiological and psychosocial conditions that characterize women with this disease.

Clear progress has been made in the field of placental pathophysiology and pharmacological research which has resulted, on the one hand, in a better understanding of the pathophysiological mechanisms of the disease, and on the other, in the development of better therapeutic options [1] [8] [9]. However, different studies that have been performed to construct an explanatory model of preeclampsia have not reached their goal. Several tentative explanations have been put forth, among which we can mention the following: the universal distribution of the disease risk factors that differ by location and ethnicity; the objective of the studies that define the methodological design of research, such that one clinical approach will use a different strategy, which is selected due to basic or epidemiological purposes. One consequence of this is the absence of an explanatory model of the disease that integrates the findings observed with different methodological approaches.

During the latter part of the 70's in the last century, the field of psychosocial epidemiology emphasized the idea or concept of "general susceptibility", in contrast to the idea of "disease specificity" or "specific exposure". John Cassel, a representative of this movement argued that psychosocial stressors generated by different variants of human interaction, such as dominant hierarchies, social disorganization, rapid social change, and marginal status with social isolation, act as non-specific exposures that alter neuroendocrine function. From the perspective of Cassel, these psychosocial factors together explain why certain social groups are particularly affected by a wide range of diseases. Moreover, this same author considered social phenomena (social support, social networks, and social capital), which hypothetically neutralize the negative impact of unfavorable psychosocial aspects important [10] [11].

The previous assumptions have been validated in numerous investigations that have addressed a variety of health problems [12]-[16]; as a result the following have been proposed:

Basic Principles in Psychosocial Epidemiology [17].

1) The distribution of psychosocial stressors and "buffers" are related to the social position of diverse populations, with their living (home, neighborhood), and working conditions.

2) Low social status can be considered the most adverse psychological stressor.

3) Psychological stress, especially chronic, can damage the health of an individual through pathways that independently or synergistically involve the CNS, regulatory physiology, behavior, and disease.

In recent years there has been increasing interest in studying the relationship between shared physical spaces or specific geographic areas (neighborhood), and health conditions of specific populations [18] [19]. Several studies have been conducted using the same ecological approaches that relate the characteristics of physical and social context, with morbidity and mortality rates, as those of multilevel designs that relate the characteristics of the socioeconomic context with the health conditions of the inhabitants [20] [21]. It is also important to point out that there are studies documenting the positive impact of remodeling physical areas and constructing recreational areas to reduce crime rates [22] [23]. This is explained by arguing that improving conditions in a physical context enables social interaction and cohesion, and modifies the perceived environment by living in a more pleasant and safe place.

Research conducted to establish a relationship between material aspects and socioeconomic status with health conditions of the population have been consistent with better health being observed in high socioeconomic strata, although perspectives have emerged that do not accept that material conditions are the only thing that explain the different levels of health. The perceptions of wellbeing and of having a favorable status, in addition to advantageous material conditions are considered solid components of psychosocial support [24]. It has also been pointed out that these groups are generally characterized by having control over a number of situations related to their family, work and social life, a situation that increases their perception of self-worth and well-being. The opposite occurs in disadvantaged groups, in which social disadvantage is included in their perception of disadvantage and lack of autonomy and control over a number of circumstances related to their social life and work.

Sterling and Eyer in 1988 advanced the psychosocial theory by introducing a new concept: allostasis. This term refers to the regulatory systems that achieve stability through change, whose purpose is not the constancy of the different indicators or biological parameters (hormonal, immunological, vascular) but adjustment to de- 
mands; this is how the body remains stable in changing environments [17]. This adjustment determines effective regulation, which involves preventing errors and minimizing costs. Both situations are achieved by the use of prior information to predict demands and adjustments to parameters, in such a way that allostasis considers the unusual value of a parameter as a response to a prediction and not as an error to defend an established point (constant). For example, oscillations in blood pressure values during the day in healthy subjects, according to different circumstances [25].

Bruce McEwen later introduced the term allostatic load, which refers to the wear and tear caused by chronic hyperactivity or hypoactivity of the systems that protect the body from internal or external stress. These systems include the autonomic nervous system, hypothalamic-pituitary-adrenal axis, and the cardiovascular, metabolic and immune systems [26] [27].

The production of allostatic mediators (hormones, chemical messengers, and neurotransmitters) occurs according to two main patterns: response to challenges or demands, as in highly stressful experiences, or as part of routine physiological functions that are controlled by daily habits such as sleep-wake cycles (regularly getting up early). Allostasis can yield to allostatic load in different ways: 1) Prolonged response. In the case of cortisol and adrenaline, there are nerve pathways that turn the system "off" when the stressor is gone. Ideally self-regulatory mechanisms must be activated when demands are high and deactivate when these disappear. When this does not occur the expression of allostatic load is imminent; 2) a lack of adaptation to repeated stressors of the same kind, with prolonged exposure to stress hormones; 3) chronic stress or "repeated hits" in response to unknown threatening events; repeated stress damages the regulatory mechanisms of allostatic response or alters the cyclical production of cortisol and adrenaline; 4) inadequate or insufficient response. An inadequate response, to cortisol, for example, can lead to overactivation of other allostatic mediators substantially altering biological regulatory mechanisms [26]. To this we must mention, genetic and epigenetic factors, characteristics of early development of the individual, or situations of the environment such as the evaluation made by individuals of their socially structured situations (threatening-rewarding, fair-unfair, with regard to their immediate circumstances and anticipated scenarios), represent conditions that are added to the influence of stress, increasing the levels of cortisol and adrenalin.

The emergence of the concepts of allostasis and allostatic load, have allowed not only a link to a variety of situations that occur in the population context of a social, economic, cultural, and psychosocial nature with the different health conditions of individuals living in these contexts, but also an explanation of the interlevel relationship of a social-individual group, that is, how the advantages or disadvantages of being part of a particular social group biologically translate [28] [29], opening a range of possibilities of cognitive nature that allow the best approach to health problems.

\section{Stating the Problem}

Although there have been numerous approaches to explain the genesis of preeclampsia, so far there is no explanation that has had universal acceptance. Epidemiological studies have focused on the search for risk factors that are associated with the increased frequency of the disease, and although there is an agreement about certain characteristics related to obstetric (primiparity, prenatal care), constitutional (overweight, malnutrition), genetic (family history of the disease) and epigenetic (DNA methylation of placental micro RNAs) conditions [2] [30] [31], a consistent association with the expression of the disease has not been shown. Regarding basic research, aspects of placental pathophysiology have been studied; specifically the two-stage model which states that placental failure causes systemic dysfunction, which exacerbates placental hypoxia causing clinical expression of the disease. Detailed study of the angiogenic and antiangiogenic factors involved in placental failure has allowed a better understanding of the pathophysiology of preeclampsia, but this has not resulted in an explanation of its genesis [6] [7]. Genetic testing and specifically, analysis of a variety of tentative polymorphisms associated with the disease have not yielded significant results [32] [33]. On the other hand, persistent patterns of prevalence and disease distribution over time, most often internationally in developing countries, the high occurrence within the same country in socially or economically disadvantaged groups, and more frequent disease in minority groups in multicultural countries [1] [34], are clear indicators that the genesis of preeclampsia is strongly associated with the conditions of development and social inequality of any country. This background enables an analysis from the perspective of psychosocial epidemiology, linking aspects of psychosocial stressors and psychosocial support (underlying social conditions that are present anywhere) in pregnant women and their relationship with indicators of allostasis and allostatic load. 


\section{Results from the Perspective of Psychosocial Epidemiology and Discussion}

There exist a number of studies that theoretically can be located within the field of the psychosocial epidemiology, oriented to clarify the existing relationship between preeclampsia and unfavorable contexts located the same in institutions as in different social and cultural backgrounds [1] [35]-[41]. Likewise, it has been observed that the excessive work with little recognition [42], belonging to a subordinated ethnic group or with clear social or economic disadvantages, are conditions that represent strong stressors which-when there are not situations of familiar, social or labor support that counteract them-infringe the adaptative regulatory mechanisms.

Although it has already been well documented this relationship of an unfavorable psychosocial environment with the clinical expression of preeclampsia, it is essential to understand the expression that these unfavorable conditions have in the biological level and specifically in indicators of allostatic load in the group of preeclamptic women.

Vianna P. et al. [43]; propose that the distress conditions during pregnancy can occasionate the development of preeclampsia by an increase in the cortisol levels, which are associated to hypertension and endothelial damage. Hogg K. et al. [44], highlight that most of normal pregnancies are characterized by the absence of placental cortisol, in contrast with the observed in women with preeclampsia, in which in more than $80 \%$ the placental cortisol is detectable, indicative of the importance that the glucocorticoids have in the development of the disease. In a case-control study nested in a cohort carried-out in Mexico, in which salivary cortisol was measured to a group of teenage pregnant participants, in two stages of the gestational course, before the $20^{\text {th }}$ week and after the $30^{\text {th }}$ week, at the 8:00, 12:00 and 20:00 hrs, the results were higher, statistically significant in the group that got sick, in the two evaluations done during the gestational process; the cutoff point established in this study as a predictor of the disease before the $20^{\text {th }}$ week through ROC curves was of $13.9 \mathrm{nmol} / \mathrm{L}$ [45].

In a case-control study conducted later also in Mexico, was observed that the salivary cortisol values obtained in the group with preeclampsia were significatively higher than the observed in the control group [46]. Although the studies directed to link the unfavorable conditions of the psychosocial environment with allostatic indicators of preeclampsia are scarce, it is considered that performing these approaches, linking the socio epidemiological characteristics with allostatic indicators of the disease will provide a better understanding of the genesis of this health problem.

\section{Conclusion}

The consistency observed in numerous works developed in different parts of the world, which have established a relationship between an adverse psychosocial environment- to which often underlies an unfavorable socioeconomic context - and clinical expression of preeclampsia [35]-[41], validates the proposals made about the importance of social determinants in conditions of health of the population [17] [47]. It is important to identify geographic areas and socioeconomic and cultural strata that record patterns of disease prevalence that show regularly over time, and systemize the physical and socio-economic conditions and cultural environment that tentatively represent risk conditions. It is also important to incorporate the analysis of aspects related to social cohesion and collective efficacy, among others [48], which represent reliable indicators of social support. The development of these studies will allow the spatial location of scenarios of socio-epidemiological risk of disease, which will be as diverse as social groups, hence the difficulty in finding a single explanatory model. The study of different contexts of risk explored in clinical variables, the allostatic mediators, as well as the identification and confirmation of diverse interactions in preeclampsia obtained using a systems biology approach [49], enable the construction of interlevel explanatory models (socio epidemiological—clinical-biological) more suited to the different social, economic and cultural realities in which the disease is developing.

\section{Conflict of Interest}

The authors declare that they have no conflicts of interests.

\section{Acknowledgments}

We kindly appreciate the technical assistance of Dr. Sergio Lozano Rodríguez, in translating this article into English. 


\section{References}

[1] Duley, L. (2009) The Global Impact of Pre-Eclampsia and Eclampsia. Seminars in Perinatology, 33, 130-137. http://dx.doi.org/10.1053/j.semperi.2009.02.010

[2] Mikat, B., Gellhaus, A., Wagner, N., Birdir, C., Kimmig, R. and Köninger, A. (2012) Early Detection of Maternal Risk for Preeclampsia. ISRN Obstetrics and Gynecology, 2012, Article ID: 172808, 7 pages.

[3] Lopez-Llera, M. (1995) Complexity and Complicity in Eclampsia: Barriers or Bridges? Medical Hypotheses, 45, 591-601. http://dx.doi.org/10.1016/0306-9877(95)90244-9

[4] Dekker, G. and Sibai, B. (2001) Primary, Secondary and Tertiary Prevention of Preeclampsia. Lancet, 357, $209-215$. http://dx.doi.org/10.1016/S0140-6736(00)03599-6

[5] Roberts, J.M. and Cooper, DW. (2001) Pathogenesis and Genetics of Preeclampsia. Lancet, 357, 53-56. http://dx.doi.org/10.1016/S0140-6736(00)03577-7

[6] Luft, F.C. (2003) Pieces of the Preeclampsia Puzzle. Nephrology Dialysis Transplantation, 18, 2209-2210. http://dx.doi.org/10.1093/ndt/gfg498

[7] Podjarny, E., Losanczy, G. and Baylis, C. (2004) Animals Models of Preeclampsia. Seminars in Perinatology, 24, 596-606. http://dx.doi.org/10.1016/ S0146-0005(99)80055-X

[8] Furuya, M., Kurasawa, K., Nagahama, K., et al. (2011) Disrupted Balance of Angiogenic and Antiangiogenic Signaling in Preeclampsia. Journal of Pregnancy, 2011, Article ID: 123717, 10 pages. http://dx.doi.org/10.1155/2011/123717

[9] Maynard, S.E., Min, J.Y., Merchan, J., et al. (2003) Excess Placental Soluble Fms-Like Tyrosine Kinase 1 (sFlt1) May Contribute to Endothelial Dysfunction, Hypertension, and Proteinuria in Preeclampsia. Journal of Clinical Investigation, 111, 649-658. http://dx.doi.org/10.1172/JCI200317189

[10] Cassel, J. (1976) The Contribution of the Social Environment to Host Resistance. American Journal of Epidemiology, 104, 107-123. http://aje.oxfordjournals.org/content/104/2/107.full.pdf+html

[11] Cassel, J. (1974) Psychosocial Processes and "Stress": Theoretical Formulation. International Journal of Health Services, 4, 471-482. http://dx.doi.org/10.2190/WF7X-Y1L0-BFKH-9QU2

[12] Cervantes, R. and Castro, F. (1985) Stress, Coping and Mexican American Mental Health: A Systematic Review. Hispanic Journal of Behavioral Science, 7, 1-73. http://dx.doi.org/10.1177/07399863850071001

[13] Sheehan, J. (1998) Stress and Low Birth Weight: A Structural Modeling Approach Using Real Life Stressors. Social Science Medicine, 47, 1503-1512. http://www.ncbi.nlm.nih.gov/pubmed/9823046

[14] Stone, A., Mezzacappa, E., Donatone, B. and Gonder, M. (1999) Psychosocial Stress and Social Support Are Associated with Prostate-Specific Antigen Levels in Men: Results from a Community Screening Program. Health Psychology, 18, 482-486. http://www.ncbi.nlm.nih.gov/pubmed/10519464

[15] Butler, L., Koopman, Ch., Classen, C. and Spiegel, D. (1999) Traumatic Stress, Life Events, and Emotional Support in women with Metastatic Breast Cancer: Cancer Related Traumatic Stress Symptoms Associated with Past and Current Stressors. Health Psychology, 18, 555-560. http://www.ncbi.nlm.nih.gov/pubmed/10619528

[16] Wamala, S.P., Mittleman, M.A., Horsten, M., Schenck-Gustafsson, K. and Orth-Gomér, K. (2000) Job Stress and the Occupational Gradient in Coronary Heart Disease Risk in Women. The Stockholm Female Coronary Risk Study. Social Science \& Medicine, 51, 481-489. http://www.ncbi.nlm.nih.gov/pubmed/10868664

[17] Krieger, N. (2011) Epidemiology and The People’s Health. Oxford \& New York: Oxford University Press. http://dx.doi.org/10.1093/acprof:0so/9780195383874.001.0001

[18] Richardson, D.M. and Nuru-Jeter, A.M. (2011) Neighborhood Contexts Experienced by Young Mexican-American Women: Enhancing Our Understanding of Risk for Early Childbearing. Journal of Urban Health: Bulletin of the New York Academy of Medicine, 89, 59-73. http://dx.doi.org/10.1007/s11524-011-9627-9

[19] Messer, L.C., Maxson, P. and Miranda, M.L. (2012) The Urban Built Environment and Associations with Women's Psychosocial Health. Journal of Urban Health: Bulletin of the New York Academy of Medicine, 90, 857-871. http://dx.doi.org/10.1007/s11524-012-9743-1

[20] Roux, A.V.D. (2001) Investigating Neighborhood and Area Effects on Health. American Journal of Public Health, 91, 1783-1789. http://dx.doi.org/10.2105/AJPH.91.11.1783

[21] Kennedy, B., Kawachi, I. and Prothrow-Stih, D. (1996) Income Distribution and Mortality: Cross Sectional Ecology Study of the Robin Hood Index in the United States. BMJ, 312, 1004-1007. http://dx.doi.org/10.1136/bmj.312.7037.1004

[22] Branas, C., Rubin, D. and Guo, W. (2012) Vacant Properties and Violence in Neighborhoods. ISRN Public Health, 2012, Article ID: 246142. http://dx.doi.org/10.5402/2012/246142

[23] Berkman, L. and Clark, C. (2003) Neighborhoods and Networks: The Construction of Safe Places and Bridges. In: Ka- 
wachi, I. and Berkman, L., Eds, Neighborhoods and Health, Oxford University Press, Oxford \& New York, 288-302. http://dx.doi.org/10.1093/acprof:oso/9780195138382.003.0013

[24] Marmot M. (2004) The Status Syndrome: How Social Standing Affects Our Health and Longevity. Henry Holt and Company, New York.

[25] Sterling, P. (2004) Principles of Allostasis: Optimal Design, Predictive Regulation, Pathophysiology, and Rational Therapeutics. In: Schulkin, J., Ed., Allostasis, Homeostasis, and the Costs of Physiological Adaptation, Cambridge University Press, Cambridge, 17-64.

[26] McEwen, B. (2007) Physiology and Neurobiology of Stress and Adaptation: Central Role of the Brain. Physiological Reviews, 87, 873-904. http://dx.doi.org/10.1152/physrev.00041.2006

[27] McEwen, B. (2007) Central Effects of Stress Hormones in Health and Disease: Understanding the Protective and Damaging Effects of Stress and Stress Mediators. European Journal of Pharmacology, 583, 174-185. http://dx.doi.org/10.1016/j.ejphar.2007.11.071

[28] McEwen, B. and Norton, E. (2004) The End of Stress as We Know It. DANA Press, Washington DC.

[29] Ganzel, B., Morris, P. and Wethington, E. (2010) Allostasis and the Human Brain: Integrating Models of Stress from the Social and Life Sciences. Physiological Reviews, 117, 134-174.

[30] Sibai, B., Dekker, G. and Kupferminc, M. (2005) Pre-Eclampsia. The Lancet, 365, 785-799. http://dx.doi.org/10.1016/S0140-6736(05)17987-2

[31] Nelissen, E.C., van Montfoort, A.P., Dumoulin, J.C. and Evers, J.L. (2011) Epigenetics and Placenta. Human Reproduction Update, 17, 397-417. http://dx.doi.org/10.1093/humupd/dmq052

[32] Wilton, A.N., Cooper, D.W., Brennecke, S.P., Bishop, S.M. and Marshall, P. (1990) Absence of Close Linkage between Maternal Genes for Susceptibility to Pre-Eclampsia/Eclampsia and HLA DRß. The Lancet, 336, 653-657. http://dx.doi.org/10.1016/0140-6736(90)92149-C

[33] Humphrey, K.E., Harrison, G.A., Cooper, D.W., Wilton, A.N., Brennecke, S.P. and Trudinger, B.J. (1995) HLA-G Deletion Polymorphism and Pre-Eclampsia/Eclampsia. BJOG: An International Journal of Obstetrics \& Gynaecology, 102, 707-710. http://dx.doi.org/10.1111/j.1471-0528.1995.tb11427.x

[34] Tanaka, M., Jaamaa, G., Kaiser, M., Hills, E., Soim, A., Zhu, M., Shcherbatykh, I.Y., et al. (2007) Racial Disparity in Hypertensive Disorders of Pregnancy in New York State: A 10-Year Longitudinal Population-Based Study. American Journal of Public Health, 97, 163-170. http://dx.doi.org/10.2105/AJPH.2005.068577

[35] Klebanoff, M., Shiono, P. and Rhoads, G. (1990) Outcomes of Pregnancy in a National Sample of Resident Physicians. The New England Journal of Medicine, 323, 1040-1045. http://dx.doi.org/10.1056/NEJM199010113231506

[36] Erickson, M. (1976) The Relationship between Psychological Variables and Specific Complications of Pregnancy, Labor and Delivery. Journal of Psychosomatic Research, 20, 207-210. http://dx.doi.org/10.1016/0022-3999(76)90022-2

[37] Herrera, J.A., Ersheng, G., Shahabuddin, A.K.M., Lixia, D., Wei, Y., Faisal, M., et al. (2006) Evaluación periódica del riesgo biopsicosocial prenatal en la predicción de las complicaciones maternas y perinatales en Asia 2002-2003. Colombia Médica, 37, 6-14. http://hdl.handle.net/10893/5594

[38] Landsbergis, P. and Hatch, M. (1996) Psychosocial Work Stress and Pregnancy-Induced Hypertension. Epidemiology, 7, 346-351.

[39] Abeysena, C., Jayawardana, P. and Seneviratne, R. (2010) Effect of Psychosocial Stress on Maternal Complications during Pregnancy: A Cohort Study. International Journal of Collaborative Research on Internal Medicine \& Public Health, 2, 436-448.

[40] Salvador, J., Martínez, Y., Lechuga, A., Terrones, A. and Ruiz, R. (2000) Situación psicosocial de las adolescentes y toxemias del embarazo. Salud Pública de México, 42, 99-105. http://www.redalyc.org/articulo.oa?id=10642205 http://dx.doi.org/10.2105/AJPH.2012.301153

[41] Salvador-Moysén, J., Martínez-López, Y., Lechuga-Quiñones, A.M. and Terrones-González, A. (2005) Hipertensión inducida por el embarazo enadolescentes: Un estudio multicéntrico. Ansiedad y Estrés, 11, 17-25. http://dialnet.unirioja.es/servlet/articulo?codigo=1197905

[42] Landsbergis, P.A., Dobson, M., Koutsouras, G. and Schnall, P. (2013) Job Strain and Ambulatory Blood Pressure: A Meta-Analysis and Systematic Review. American Journal of Public Health, 103, e61-e71. http://dx.doi.org/10.2105/AJPH.2012.301153

[43] Vianna, P., Bauer, M., Dornfeld, D. and Chies, J.A. (2011) Distress Conditions during Pregnancy May Lead to PreEclampsia by Increasing Cortisol Levels and Altering Lymphocyte Sensitivity to Glucocorticoids. Medical Hypotheses, 77, 188-191. http://dx.doi.org/10.1016/j.mehy.2011.04.007

[44] Hogg, K., Blair, J.D., McFadden, D.E., von Dadelszen, P. and Robinson, W.P. (2013) Early Onset Pre-Eclampsia Is Associates with Altered DNA Methylation of Cortisol-Signalling and Steroidogenic Genes in the Placenta. PLoS ONE, 
8, e62969. http://dx.doi.org/10.1371/journal.pone.0062969

[45] Salvador-Moysén, J., Ramírez-Aranda, J.M., Martínez-López, Y. and Aguilar-Durán, M. (2012) Salivary Cortisol Levels as a Predictor of Preeclampsia in Adolescents. Colombia Médica, 43, 46-53. http://www.redalyc.org/articulo.oa?id=28323202006

[46] Aguilar-Durán, M. (2012) Estudio de los polimorfismos -800G/A, -509C/T y 869T/C del gen TG $\beta 1$ y del cortisol salivario en el desarrollo de preeclampsia en adolescentes embarazadas. Ph.D. Dissertation, Universidad Juárez del Estado de Durango, Durango.

[47] Viniegra, L. (2003) Hacia un concepto de salud colectiva. In: Viniegra, L., Ed., La crítica: Aptitud olvidada por la educación, 2nd Edition, Instituto Mexicano del Seguro Social, Ciudad de México, 89-107.

[48] Sampson, R.J. (2003) Neighborhood-Level Context and Health: Lessons from Sociology. In: Kawachi, I. and Berkman, L., Eds., Neighborhoods and Health, Oxford University Press, Oxford \& New York, 132-146. http://dx.doi.org/10.1093/acprof:0so/9780195138382.003.0006

[49] Tejera, E., Bernardes, J. and Rebelo, I. (2012) Preeclampsia: A Bioinformatics Approach through Protein-Protein Interaction Networks Analysis. BMC Systems Biology, 6, 97. http://www.biomedcentral.com/1752-0509/6/97 
Scientific Research Publishing (SCIRP) is one of the largest Open Access journal publishers. It is currently publishing more than 200 open access, online, peer-reviewed journals covering a wide range of academic disciplines. SCIRP serves the worldwide academic communities and contributes to the progress and application of science with its publication.

Other selected journals from SCIRP are listed as below. Submit your manuscript to us via either submit@scirp.org or Online Submission Portal.
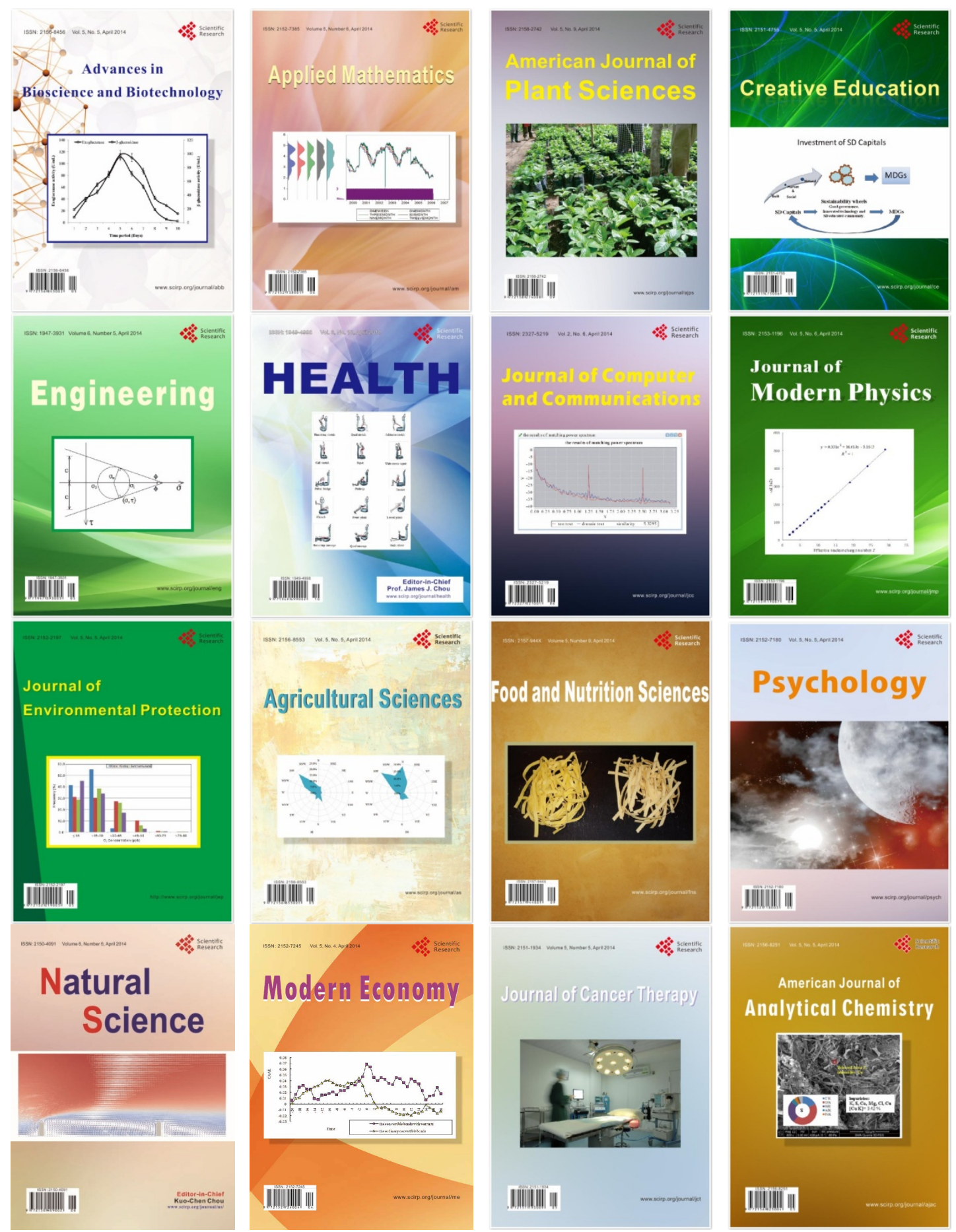